\title{
An Economic Order Quantity Model with Completely Backordering and Nondecreasing Demand under Two-Level Trade Credit
}

\author{
Zohreh Molamohamadi, ${ }^{1}$ Rahman Arshizadeh, ${ }^{2}$ Napsiah Ismail, ${ }^{1}$ and Amir Azizi ${ }^{3}$ \\ ${ }^{1}$ Department of Mechanical and Manufacturing Engineering, University Putra Malaysia, 43400 Serdang, Selangor, Malaysia \\ ${ }^{2}$ Department of Computer Engineering, Islamic Azad University, Science and Research Branch, Simon Boulevard, \\ Ashrafi Esfahani Highway, Tehran 1477893855, Iran \\ ${ }^{3}$ Faculty of Manufacturing Engineering, Universiti Malaysia Pahang, 26600 Pekan, Pahang, Malaysia
}

Correspondence should be addressed to Zohreh Molamohamadi; zmmohamadi@gmail.com

Received 31 July 2014; Accepted 5 December 2014; Published 31 December 2014

Academic Editor: David Bulger

Copyright (C) 2014 Zohreh Molamohamadi et al. This is an open access article distributed under the Creative Commons Attribution License, which permits unrestricted use, distribution, and reproduction in any medium, provided the original work is properly cited.

\begin{abstract}
In the traditional inventory system, it was implicitly assumed that the buyer pays to the seller as soon as he receives the items. In today's competitive industry, however, the seller usually offers the buyer a delay period to settle the account of the goods. Not only the seller but also the buyer may apply trade credit as a strategic tool to stimulate his customers' demands. This paper investigates the effects of the latter policy, two-level trade credit, on a retailer's optimal ordering decisions within the economic order quantity framework and allowable shortages. Unlike most of the previous studies, the demand function of the customers is considered to increase with time. The objective of the retailer's inventory model is to maximize the profit. The replenishment decisions optimally are obtained using genetic algorithm. Two special cases of the proposed model are discussed and the impacts of parameters on the decision variables are finally investigated. Numerical examples demonstrate the profitability of the developed two-level supply chain with backorder.
\end{abstract}

\section{Introduction}

Since the introduction of the classical economic order quantity (EOQ) model by Harris [1], many researchers have extended it in several ways. One of the discussed issues in this area is including delay in payment, as an incentive system, in the EOQ or economic production quantity (EPQ) models [2]. According to Piasecki [3] and Molamohamadi et al. [4], different types of delay in payment can be classified as (1) pay as sold, (2) pay as sold during a predefined period, (3) pay after a predefined period, and (4) pay at the next consignment order.

In the first type of delay in payment, so-called consignment inventory, the buyer defers paying for the items till they are sold to the customers. The second type refers to the case that the buyer pays off as soon as he sells the items to the customers during a predefined period. At the end of this period, he can either pay for the remaining items in his stock or return the unsold items to the vendor. According to the third type of delay in payment, which is known as trade credit in the literature, the buyer must pay to the vendor at the end of a predetermined period. During the credit period, the buyer sells the items to his customers and accumulates revenue and earns interest. After this period, however, he would be charged a higher interest if the payment is not settled. Based on the fourth type, the payment for each order would be settled at the time of the next replenishment order. Therefore, there is one replenishment cycle delay for each received order in this type. The advantage of delay in payment contract to the buyer is obvious; he does not need to invest his capital in inventory and can earn interest for the items he sells. Moreover, the vendor can apply this agreement as a sales promotional tool for attracting new buyers and selling new and unproven products.

As this paper focuses on the third type of delay in payment, we review the literature related to trade credit (please 
refer to Seifert et al. [5] and Molamohamadi et al. [6]). Goyal [7] presented an EOQ mathematical model for determining the economic order quantity where the supplier offers a fixed credit period to the retailer to settle the account. His paper is the infrastructure for its following studies. Aggarwal and Jaggi [8] extended Goyal [7] by considering deterioration rate and assuming that the customer accumulates the sales revenue and earns interest during the credit period and beyond it. Jamal et al. [9] included shortages in the proposed model by Aggarwal and Jaggi [8] to generalize it. Teng [10] modified Goyal's [7] model by distinguishing between the unit purchase cost and the selling price. By applying an EPQ model, Chung and Huang [11] further developed Goyal [7] by assuming finite replenishment rate. Huang [12] considered a two-level trade credit and deduced Goyal [7] as a special case of his research. In a two-level trade credit, not only does the vendor offer trade credit to the buyer, but the retailer also provides a credit period to his customers.

Huang [13] investigated the retailer's inventory policy under two-level trade credit with unequal selling and purchasing prices and extended Teng [10] and Huang [12] by considering the retailer's limited storage space. Teng and Goyal [14] complemented the shortcoming of Huang [12]'s model in calculating the earned interest from the time the retailer is paid by his customers, not from time zero. They further extended his paper by relaxing the limitations on the selling and purchasing prices, as well as retailer and customer's credit periods. Huang [15] established an economic order quantity model in which the supplier provides the retailer partially permissible delay in payment for the order quantities smaller than a predetermined quantity and offers him complete trade credit otherwise. Huang [16] differentiated between the purchase cost and the selling price and presented an EPQ model under two levels of trade credit to generalize Chung and Huang [11] and Huang [12]. Teng and Chang [17] reformulated Huang's [16] model by calculating the retailer's earned revenue from the time he is paid by the customers and further extended his model by assuming that the customer's credit period is not inevitably smaller than the retailer's delay period. Su [18] developed a supplier-buyer inventory model in which the supplier's selling price is dependent on his productions cost. He further assumed that the latter is affected by the market demand and production rates, and the production rate is sensitive to the price dependent market demand. He finally obtained the optimal pricing, ordering, and inventory decisions of a profit maximizing system under trade credit contract.

Dye and Ouyang [19] proposed an EOQ mixed-integer nonlinear programming model under two levels of trade credit for deteriorating items with time-varying demand and applied a traditional particle swarm optimization (PSO) algorithm to determine the optimal selling price and replenishment policy. Dye [20] applied PSO algorithm to obtain the optimal replenishment decisions of an EOQ model with price and time dependent demand, partially backlogged items, and deterioration under two-level trade credit policy. Mahata [21] presented a generalization of Goyal [7], Chung and Huang [11], Huang [12], and Huang [16] where an economic production quantity model is formulated for exponentially deteriorating items under two levels of trade credit with the assumption that the customer's partial credit period is not necessarily smaller than the retailer's complete credit agreement. Lou and Wang [22] formulated an EPQ inventory model for defective items under two independent levels of trade credit to extend some of the previous studies including Goyal [7], Teng [10], Huang [12], and Teng and Goyal [14].

Having applied cuckoo search algorithm, Molamohamadi et al. [23] solved an EPQ model of an exponentially deteriorating item with price-sensitive demand under trade credit contract and allowable shortages. Chern et al. [24, 25] formulated a supply chain under trade credit financing with noncooperative Stackelberg and Nash equilibrium solutions, respectively. Chen and Teng [26] determined the retailer's optimal cycle time by developing an EOQ model under trade credit policy for continuously deteriorating items with maximum lifetime. Chen et al. [27] reformulated Mahata's [21] proposed model by calculating the earned and paid interest based on the facts that (i) the retailer earns interest from the time he is paid by the customers and (ii) the retailer's interest payable must be calculated based on the total items in stock, not only on the unsold finished products. Some of the previous models such as Goyal [7] and Teng [10] are mentioned as special cases of their proposed model. Chen et al. [28] complemented some shortcomings of Huang's [15] mathematical expressions and figures and proposed a simple method to solve the inventory problem.

Reviewing the literature clarifies that trade credit has received great attention of the researchers, while it has still outstanding space for further studies. For instance, it is mostly assumed that the demand rate is constant. However, recently, Teng et al. [29] developed an EOQ inventory model under trade credit contract in which demand has an increasing function of time. Although, their model can be considered as a generalization of its preceding studies, it has great potential for further extension. As it is stated in Jamal et al. [9], when delay in payment is assumed, shortages are more important as they affect the quantity ordered to benefit from the delay in payment. Moreover, in practices, not only does the supplier propose a delay period to the retailer, but the retailer also allows his customers to defer their payment. Thus, considering two levels of trade credit contributes to practical situations.

Considering the gaps in the literature, we extend the proposed model of Teng et al. [29] to the case of backorder and two-level trade credit. It is assumed here that the retailer's credit period offered by the supplier is greater than the customer's delay period offered by the retailer. The proper replenishment policy and the maximum profit of the retailer are then obtained by applying genetic algorithm (GA). It is finally deduced that the inventory system of Teng et al. [29] and the traditional inventory system are special cases of our proposed model and the results obtained in this paper are compared with these cases.

The rest of this paper is organized as follows. Section 2 lays out the notations and assumptions used in the modeling of the problem. The model is formulated in Section 3 and the two special cases of the presented model presented are discussed in Section 4. The genetic algorithm, used for 
solving the model, is described in Section 5. Regarding the numerical examples of Teng et al. [29], Section 6 provides some numerical examples and the conclusion is finally discussed in Section 7.

\section{Notations and Assumptions}

The following notations and assumptions are used in this paper.

\subsection{Notations}

$A$ : ordering cost per order,

$c$ : unit purchasing cost,

$s$ : unit selling price (with $s>c$ ),

$h$ : unit stock holding cost per unit of time (excluding interest charges),

$c_{b}$ : unit backorder cost of retailer per unit of time,

$I_{e}$ : interest which can be earned per \$ per unit of time by the retailer,

$I_{c}$ : interest charges per $\$$ in stocks per unit of time by the supplier,

$M$ : the retailer's trade credit period offered by supplier in years,

$N$ : the customer's trade credit period offered by retailer in years,

NP: the net profit of the retailer per unit of time,

$T$ : the inventory cycle time,

$T_{1}$ : the inventory cycle time with positive stock,

$Q$ : the retailer's order quantity,

$Q_{1}$ : the inventory consumed in $T_{1}$.

\subsection{Assumptions}

(1) The demand is assumed to have an increasing function of time and is defined by $D(t)$ as follows:

$$
D(t)=a+b t,
$$

where $a$ and $b$ are nonnegative constants and $t$ is the growth stage of the product life cycle.

(2) Shortages are allowed and completely backordered.

(3) The lead time is zero.

(4) The retailer is offered a delay period $(M)$ by the supplier and provides the customers with a shorter credit period $(N)$. The retailer pays off to the supplier at the end of the credit period $(M)$ and pays for the interest charges on the remaining items in his stock with rate $I_{c}$ during $\left[M, T_{1}\right]$ if $T_{1} \geq M$. When the credit period is greater than the positive-stock replenishment cycle, the retailer would not be charged by any interest after settling the account.

(5) The retailer accumulates revenue and earns interest with rate $I_{e}$ from $N$ to $M$.

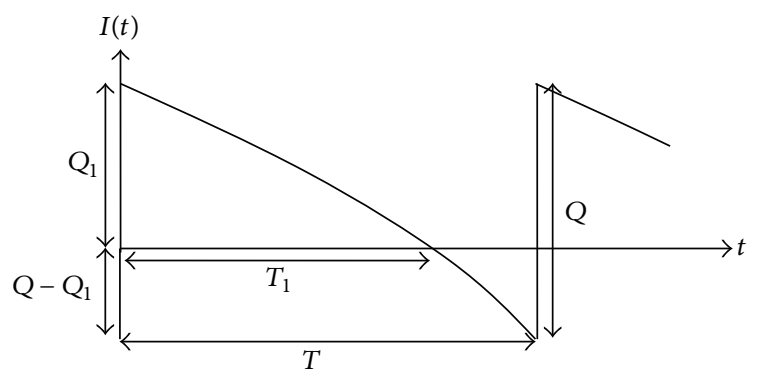

FIGURE 1: Inventory level at the manufacturer from 0 to $T$.

\section{Mathematical Formulation}

According to the notations and assumptions discussed in previous section, the retailer's inventory system is depicted in Figure 1 and can be explained as follows. The retailer orders and receives $Q$ units of items at time zero and sends the previously backlogged orders to the customers immediately. The remaining inventory $\left(Q_{1}\right)$ depletes gradually due to the customers' demand and becomes zero at time $t=T_{1}$. From $T_{1}$ to $T$ there is no inventory on hand and the arriving orders would be backlogged to the next cycle.

Now the inventory level at time $t$ can be described by the following differential equation:

$$
\frac{d I(t)}{d t}=-D(t)=-(a+b t), \quad 0 \leq t \leq T,
$$

with the boundary condition $I\left(T_{1}\right)=0$. Therefore, the solution to (2) would be

$$
I(t)=a\left(T_{1}-t\right)+\frac{1}{2} b\left(T_{1}^{2}-t^{2}\right) .
$$

According to (3), the inventory levels at the beginning and at the end of the replenishment cycle are as (4) and (5), respectively:

$$
\begin{gathered}
Q_{1}=I(0)=a T_{1}+\frac{1}{2} b T_{1}^{2}, \\
I(T)=Q_{1}-Q=a\left(T_{1}-T\right)+\frac{1}{2} b\left(T_{1}^{2}-T^{2}\right) .
\end{gathered}
$$

Since the retailer is encountered with backorder during $T_{1}$ to $T$, and as $T_{1}<T$, (5) is smaller than zero. So, the retailer's order size per cycle time can be obtained as follows:

$$
Q=I(0)+|I(T)|=a T+\frac{1}{2} b T^{2} .
$$

The retailer's net profit consists of the following elements.

(a) The ordering cost $=A$.

(b) The inventory holding cost excluding interest charges $=h \int_{0}^{T_{1}} I(t) d t=h\left((1 / 2) a T_{1}^{2}+(1 / 3) b T_{1}^{3}\right)$.

(c) The backorder cost $=-c_{b} \int_{T_{1}}^{T} I(t) d t=c_{b}[(1 / 2) a(T-$ $\left.\left.T_{1}\right)^{2}+(1 / 6) b\left(T^{3}-3 T T_{1}^{2}+2 T_{1}^{3}\right)\right]$.

(d) The purchasing cost $=c Q=c\left[a T+(1 / 2) b T^{2}\right]$. 
TABle 1: Obtained replenishment policy for Example 1.

\begin{tabular}{|c|c|c|c|c|c|c|}
\hline & $c_{b}$ & 5 & 10 & 15 & 20 & 25 \\
\hline \multirow{5}{*}{$N=1 / 15$} & $T_{1}$ & 0.1410 & 0.1402 & 0.1400 & 0.1399 & 0.1399 \\
\hline & $T$ & 0.1562 & 0.1478 & 0.1450 & 0.1437 & 0.1429 \\
\hline & $Q_{1}$ & 531.4042 & 528.2017 & 527.4393 & 527.1146 & 526.9379 \\
\hline & $Q$ & 591.7789 & 558.1185 & 547.3368 & 542.0218 & 538.8565 \\
\hline & NP & 1690.9209 & 1683.4107 & 1680.8347 & 1679.5318 & 1678.7452 \\
\hline \multirow{5}{*}{$N=1 / 14$} & $T_{1}$ & 0.1411 & 0.1403 & 0.1401 & 0.1400 & 0.1400 \\
\hline & $T$ & 0.1563 & 0.1479 & 0.1451 & 0.1438 & 0.1430 \\
\hline & $Q_{1}$ & 532.0320 & 528.8021 & 527.9499 & 527.6089 & 527.4223 \\
\hline & $Q$ & 592.1829 & 558.6094 & 547.7684 & 542.4564 & 539.2929 \\
\hline & NP & 1690.6480 & 1683.2006 & 1680.6468 & 1679.3554 & 1678.5758 \\
\hline \multirow{5}{*}{$N=1 / 13$} & $T_{1}$ & 0.1413 & 0.1401 & 0.1402 & 0.1401 & 0.1399 \\
\hline & $T$ & 0.1564 & 0.1476 & 0.1452 & 0.1439 & 0.1429 \\
\hline & $Q_{1}$ & 532.5723 & 528.0781 & 528.3549 & 527.9951 & 527.1334 \\
\hline & $Q$ & 592.4417 & 557.6453 & 548.0746 & 542.7680 & 538.9143 \\
\hline & NP & 1690.3864 & 1683.0136 & 1680.4869 & 1679.2091 & 1678.4376 \\
\hline
\end{tabular}

In the whole table $\mathrm{NP}=\mathrm{NP}_{3}$.

TABLE 2: Obtained replenishment policy for the traditional case of Example 1 .

\begin{tabular}{lccccc}
\hline$c_{b}$ & 5 & 10 & 15 & 20 & 25 \\
\hline$T_{1}$ & 0.1338 & 0.1334 & 0.1333 & 0.1333 & 0.1334 \\
$T$ & 0.1492 & 0.1411 & 0.1385 & 0.1371 & 0.1365 \\
$Q_{1}$ & 503.0591 & 501.4132 & 501.3869 & 501.1447 & 501.7134 \\
$Q$ & 563.9292 & 531.6733 & 521.5435 & 516.2486 & 513.8079 \\
$\mathrm{NP}$ & 1674.7187 & 1666.6643 & 1663.8890 & 1662.4829 & 1661.6331 \\
\hline
\end{tabular}

(e) The sales revenue $=s Q=s\left[a T+(1 / 2) b T^{2}\right]$.

(f) Interest payable: for calculating the interest payable, two cases must be considered.

Case $1\left(T_{1} \leq M\right)$. Since the delay period is greater than the cycle time in this case, the retailer does not have any stock on hand at the time of paying to the supplier. So, the interest charged in this case equals zero.

Case $2\left(T_{1} \geq M\right)$. In this case, the retailer would be charged for the on-hand inventory between $M$ and $T_{1}$ with the rate $I_{c}$. Therefore, the interest payable is

$$
\begin{aligned}
c I_{c}=\int_{M}^{T_{1}} I(t) d t=c I_{c}[ & \frac{1}{2} a\left(T_{1}-M\right)^{2}+\frac{1}{2} b T_{1}^{2}\left(T_{1}-M\right) \\
& \left.-\frac{1}{6} b\left(T_{1}^{3}-M^{3}\right)\right] .
\end{aligned}
$$

(g) Interest earned; according to assumption 5, the retailer would start earning interest for the items sold, from the time they are being paid by the customers $(N)$ until $M$, when the retailer must pay to the supplier. Hence, there are two cases to discuss.
Case $1\left(M-N \leq T_{1}\right)$. The retailer receives the payment for $Q-$ $Q_{1}$ items from the customers at time $N$ and then the payment will be settled with the rate $a+b t$ for the rest items. This case is illustrated in Figure 2.

Supposing the revenue function as $R(t)$, for $N \leq t \leq T_{1}+$ $N$, we have

$$
\frac{d R(t)}{d t}=a+b t, \quad N \leq t \leq T_{1}+N, \quad R(N)=0 .
$$

The solution to this equation is

$$
R(t)=a(t-N)+\frac{1}{2} b(t-N)^{2} .
$$

So, the function for $N \leq t \leq T_{1}+N$ is

$$
R(t)=a(t-N)+\frac{1}{2} b(t-N)^{2} .
$$

Now the interest earned per cycle when $M-N \leq T_{1}$ can be computed as

$$
\begin{aligned}
s I_{e}\left\{\int_{N}^{M} R(t) d t+\left(Q-Q_{1}\right)(M-N)\right\} & \\
= & s I_{e}\left\{\left(\frac{a}{2}(M-N)^{2}+\frac{b}{6}(M-N)^{3}\right)\right. \\
& \left.+\left(a\left(T-T_{1}\right)+\frac{1}{2} b\left(T^{2}-T_{1}^{2}\right)\right)(M-N)\right\} .
\end{aligned}
$$


TABLE 3: Obtained replenishment policy for Example 2.

\begin{tabular}{|c|c|c|c|c|c|c|}
\hline & $c_{b}$ & 5 & 10 & 15 & 20 & 25 \\
\hline \multirow{5}{*}{$N=1 / 15$} & $T_{1}$ & 0.0822 & 0.0839 & 0.0846 & 0.0850 & 0.0851 \\
\hline & $T$ & 0.0989 & 0.0924 & 0.0903 & 0.0893 & 0.0886 \\
\hline & $Q_{1}$ & 303.8926 & 310.4945 & 312.9991 & 314.6264 & 315.1490 \\
\hline & $Q$ & 367.6386 & 342.9968 & 334.8354 & 331.0722 & 328.3378 \\
\hline & NP & $1605.1604^{*}$ & 1590.9873 & 1585.8947 & 1583.2705 & 1581.6701 \\
\hline \multirow{5}{*}{$N=1 / 14$} & $T_{1}$ & 0.0822 & 0.0839 & 0.0846 & 0.0850 & 0.0868 \\
\hline & $T$ & 0.0989 & 0.0924 & 0.0903 & 0.0893 & 0.0903 \\
\hline & $Q_{1}$ & 304.0934 & 310.4480 & 313.2649 & 314.7091 & 321.3629 \\
\hline & Q & 367.5960 & 342.7112 & 335.0242 & 331.1502 & 334.7725 \\
\hline & NP & $1604.7161^{*}$ & 1590.6403 & 1585.5848 & 1582.9800 & 1581.3497 \\
\hline \multirow{5}{*}{$N=1 / 13$} & $T_{1}$ & 0.0824 & 0.0841 & 0.0847 & 0.0850 & 0.0853 \\
\hline & $T$ & 0.0989 & 0.0926 & 0.0904 & 0.0893 & 0.0887 \\
\hline & $Q_{1}$ & 304.6805 & 311.2158 & 313.6500 & 314.7649 & 315.7399 \\
\hline & $Q$ & 367.9643 & 343.4857 & 335.3263 & 331.0772 & 328.8301 \\
\hline & NP & $1604.2874^{*}$ & 1590.3300 & 1585.3184 & 1582.7368 & 1581.1625 \\
\hline
\end{tabular}

${ }^{*} \mathrm{NP}=\mathrm{NP}_{2}$. For the rest, $\mathrm{NP}=\mathrm{NP}_{1}$.

TABLE 4: Obtained replenishment policy for the traditional case of Example 2.

\begin{tabular}{lccccc}
\hline$c_{b}$ & 5 & 10 & 15 & 20 & 25 \\
\hline$T_{1}$ & 0.0785 & 0.0804 & 0.0811 & 0.0819 & 0.0876 \\
$T$ & 0.0952 & 0.0890 & 0.0869 & 0.0863 & 0.0913 \\
$Q_{1}$ & 290.0597 & 297.2694 & 299.9274 & 302.9720 & 324.4927 \\
$Q$ & 353.7538 & 329.8431 & 321.8196 & 319.5002 & 338.7249 \\
NP & 1595.8190 & 1581.0432 & 1575.7132 & 1572.9602 & 1570.7055 \\
\hline
\end{tabular}

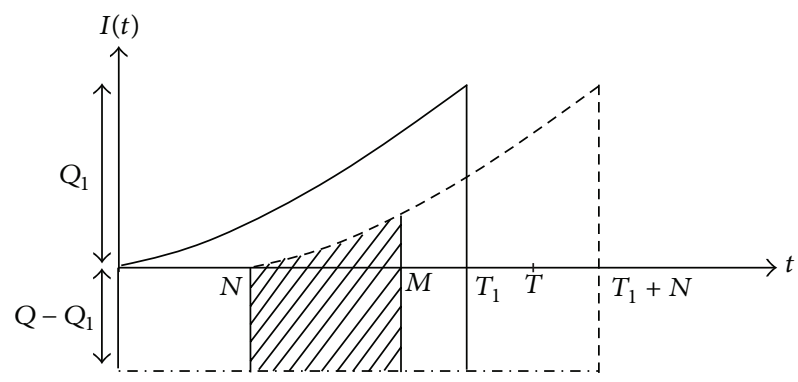

Figure 2: Accumulation of interest earned when $M-N \leq T_{1}$.

Case $2\left(M-N \geq T_{1}\right)$. According to Figure 3 , the retailer's earned interest in this case is

$$
\begin{gathered}
s I_{e}\left\{\int_{N}^{T_{1}+N} R(t) d t+\left(Q-Q_{1}\right)(M-N)+Q_{1}\left(M-T_{1}-N\right)\right\} \\
=s I_{e}\left\{\left(\frac{a}{2} T_{1}^{2}+\frac{b}{6} T_{1}^{3}\right)+\left(a\left(T-T_{1}\right)+\frac{b}{2}\left(T^{2}-T_{1}^{2}\right)\right)\right. \\
\left.\times(M-N)+\left(a T_{1}+\frac{b}{2} T_{1}^{2}\right)\left(M-T_{1}-N\right)\right\} .
\end{gathered}
$$

Based on the charged and earned interests, three general cases must be considered for modeling the retailer's net profit

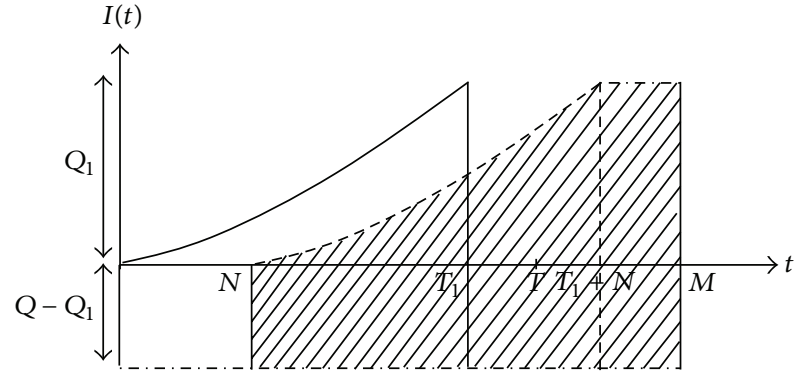

Figure 3: Accumulation of interest earned when $M-N \geq T_{1}$.

per unit time $(\mathrm{NP}(T))$ which is calculated as (revenue ordering cost - purchasing cost - holding cost - backordering cost - interest payable + interest earned)/T:

$$
\mathrm{NP}\left(T_{1}, T\right)= \begin{cases}\mathrm{NP}_{1}\left(T_{1}, T\right), & M \leq T_{1} \\ \mathrm{NP}_{2}\left(T_{1}, T\right), & T_{1} \leq M \leq T_{1}+N \\ \mathrm{NP}_{3}\left(T_{1}, T\right), & M \geq T_{1}+N,\end{cases}
$$

where

$$
\begin{aligned}
& \mathrm{NP}_{1}\left(T_{1}, T\right) \\
& =\frac{(s-c)}{T}\left[a T+\frac{1}{2} b T^{2}\right]-\frac{A}{T}-\frac{h}{T}\left(\frac{1}{2} a T_{1}^{2}+\frac{1}{3} b T_{1}^{3}\right) \\
& -\frac{c_{b}}{T}\left[\frac{1}{2} a\left(T-T_{1}\right)^{2}+\frac{1}{6} b\left(T^{3}-3 T T_{1}^{2}+2 T_{1}^{3}\right)\right] \\
& -\frac{c I_{c}}{T}\left[\frac{1}{2} a\left(T_{1}-M\right)^{2}+\frac{1}{2} b T_{1}^{2}\left(T_{1}-M\right)-\frac{1}{6} b\left(T_{1}^{3}-M^{3}\right)\right] \\
& +\frac{s I_{e}}{T}\left\{\left(\frac{a}{2}(M-N)^{2}+\frac{b}{6}(M-N)^{3}\right)\right. \\
& \left.\quad+\left(a\left(T-T_{1}\right)+\frac{1}{2} b\left(T^{2}-T_{1}^{2}\right)\right)(M-N)\right\}
\end{aligned}
$$


TABLE 5: Obtained replenishment policy for Example 3.

\begin{tabular}{|c|c|c|c|c|c|c|}
\hline & $c_{b}$ & 5 & 10 & 15 & 20 & 25 \\
\hline \multirow{5}{*}{$N=1 / 15$} & $T_{1}$ & 0.1440 & 0.1445 & 0.1453 & 0.1443 & 0.1443 \\
\hline & $T$ & 0.1597 & 0.1523 & 0.1506 & 0.1483 & 0.1474 \\
\hline & $Q_{1}$ & 542.3339 & 544.1482 & 547.5471 & 543.6133 & 543.3533 \\
\hline & $Q$ & 604.1778 & 575.0968 & 568.2234 & 559.0530 & 555.6941 \\
\hline & $\mathrm{NP}$ & 1694.5580 & 1686.7691 & 1684.0872 & 1682.7359 & 1681.9173 \\
\hline \multirow{5}{*}{$N=1 / 14$} & $T_{1}$ & 0.1455 & 0.1450 & 0.1459 & 0.1448 & 0.1448 \\
\hline & $T$ & 0.1613 & 0.1528 & 0.1511 & 0.1487 & 0.1479 \\
\hline & $Q_{1}$ & 548.2020 & 546.0887 & 549.6271 & 545.5131 & 545.4294 \\
\hline & $Q$ & 610.4544 & 577.0097 & 570.3747 & 560.9377 & 557.7669 \\
\hline & NP & 1693.8558 & 1686.1022 & 1683.4340 & 1682.0905 & 1681.2763 \\
\hline \multirow{5}{*}{$N=1 / 13$} & $T_{1}$ & 0.1461 & 0.1451 & 0.1454 & 0.1449 & 0.1458 \\
\hline & $T$ & 0.1618 & 0.1529 & 0.1506 & 0.1487 & 0.1490 \\
\hline & $Q_{1}$ & 550.3455 & 546.6795 & 547.6956 & 545.6541 & 549.4377 \\
\hline & $Q$ & 612.5216 & 577.4625 & 568.2460 & 560.9213 & 561.8045 \\
\hline & NP & 1693.0960 & 1685.3898 & 1682.7439 & 1681.4036 & 1680.5950 \\
\hline
\end{tabular}

In the whole table $\mathrm{NP}=\mathrm{NP}_{1}$.

TABLE 6: Obtained replenishment policy for the traditional case of Example 3.

\begin{tabular}{lccccc}
\hline$c_{b}$ & 5 & 10 & 15 & 20 & 25 \\
\hline$T_{1}$ & 0.1308 & 0.1308 & 0.1310 & 0.1309 & 0.1307 \\
$T$ & 0.1461 & 0.1384 & 0.1361 & 0.1347 & 0.1337 \\
$Q_{1}$ & 490.6748 & 490.4136 & 491.4703 & 490.7945 & 490.0092 \\
$Q$ & 550.6563 & 520.3205 & 511.4378 & 505.7431 & 501.9317 \\
$\mathrm{NP}$ & 1668.1513 & 1660.1071 & 1657.3286 & 1655.9201 & 1655.0680 \\
\hline
\end{tabular}

$$
\begin{aligned}
& \mathrm{NP}_{2}\left(T_{1}, T\right) \\
& =\frac{(s-c)}{T}\left[a T+\frac{1}{2} b T^{2}\right]-\frac{A}{T}-\frac{h}{T}\left(\frac{1}{2} a T_{1}^{2}+\frac{1}{3} b T_{1}^{3}\right) \\
& -\frac{c_{b}}{T}\left[\frac{1}{2} a\left(T-T_{1}\right)^{2}+\frac{1}{6} b\left(T^{3}-3 T T_{1}^{2}+2 T_{1}^{3}\right)\right] \\
& +\frac{s I_{e}}{T}\left\{\left(\frac{a}{2}(M-N)^{2}+\frac{b}{6}(M-N)^{3}\right)\right. \\
& \left.+\left(a\left(T-T_{1}\right)+\frac{1}{2} b\left(T^{2}-T_{1}^{2}\right)\right)(M-N)\right\},
\end{aligned}
$$$$
\mathrm{NP}_{3}\left(T_{1}, T\right)
$$$$
\begin{aligned}
&= \frac{(s-c)}{T}\left[a T+\frac{1}{2} b T^{2}\right]-\frac{A}{T}-\frac{h}{T}\left(\frac{1}{2} a T_{1}^{2}+\frac{1}{3} b T_{1}^{3}\right) \\
&-\frac{c_{b}}{T}\left[\frac{1}{2} a\left(T-T_{1}\right)^{2}+\frac{1}{6} b\left(T^{3}-3 T T_{1}^{2}+2 T_{1}^{3}\right)\right] \\
&+s_{e}\left\{\left(\frac{a}{2} T_{1}^{2}+\frac{b}{6} T_{1}^{3}\right)+\left(a\left(T-T_{1}\right)+\frac{b}{2}\left(T^{2}-T_{1}^{2}\right)\right)\right. \\
&\left.\times(M-N)+\left(a T_{1}+\frac{b}{2} T_{1}^{2}\right)\left(M-T_{1}-N\right)\right\} .
\end{aligned}
$$

Based on these models and according to (13), it can be verified that, in $T_{1}=M, \mathrm{NP}_{1}\left(T_{1}, T\right)=\mathrm{NP}_{2}\left(T_{1}, T\right)$, and $T_{1}=$ $M-N$ implies that $\mathrm{NP}_{2}\left(T_{1}, T\right)=\mathrm{NP}_{3}\left(T_{1}, T\right)$.

Thus, our problem is

$$
\begin{array}{ll}
\text { Maximize } & \mathrm{NP}\left(T_{1}, T\right) \\
\text { Subject to } & T_{1} \leq T .
\end{array}
$$

This is a nonlinear maximization problem which is going to be solved to obtain the optimal values of $T_{1}$ and $T$ and compute $Q_{1}$ and $Q$ accordingly based on (4) and (6).

\section{Special Cases}

This section discusses the two special cases of the inventory system proposed in the last section, the model of Teng et al. [29] and the traditional EOQ model with backorder.

Case 1. Setting $N=0, c_{b}=0$, and $T_{1}=T$, the following result is achieved:

$$
\begin{aligned}
& \mathrm{NP}_{1}\left(T_{1}, T\right) \\
&= \frac{(s-c)}{T}\left[a T+\frac{b}{2} T^{2}\right]-\frac{A}{T}-\frac{h}{T}\left(\frac{a}{2} T^{2}+\frac{b}{3} T^{3}\right) \\
&-\frac{c I_{c}}{T}\left[\frac{a}{2}(T-M)^{2}+\frac{b}{2} T^{2}(T-M)-\frac{b}{6}\left(T^{3}-M^{3}\right)\right] \\
&+\frac{s I_{e}}{T}\left(\frac{a}{2} M^{2}+\frac{b}{6} M^{3}\right), \quad M \leq T \\
& \mathrm{NP}_{3}\left(T_{1}, T\right) \\
&=\frac{(s-c)}{T}\left[a T+\frac{b}{2} T^{2}\right]-\frac{A}{T}-\frac{h}{T}\left(\frac{a}{2} T^{2}+\frac{b}{3} T^{3}\right)
\end{aligned}
$$




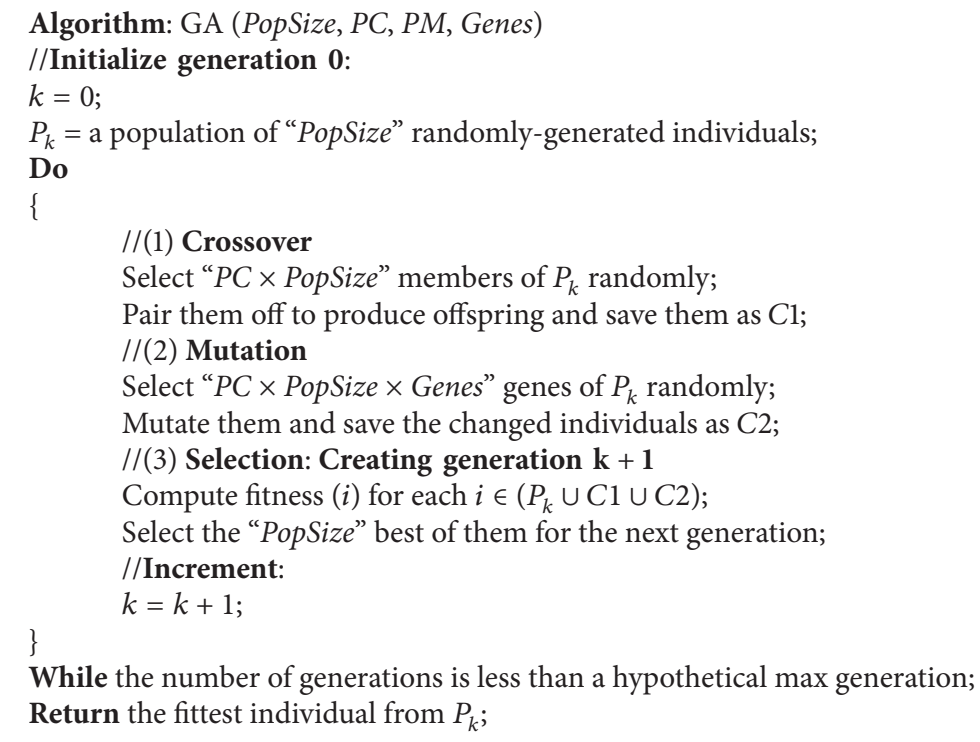

Pseudocode 1: The pseudocode of the applied genetic algorithm.

$$
\begin{array}{r}
+\frac{s I_{e}}{T}\left\{\left(\frac{a}{2} T^{2}+\frac{b}{6} T^{3}\right)+\left(a T+\frac{b}{2} T^{2}\right)(M-T)\right\}, \\
M \geq T,
\end{array}
$$

which are equal to $\prod_{2}(t)$ and $\prod_{1}(t)$ in Teng et al. [29], respectively.

Moreover, it can be certified that when $M=T$, $\mathrm{NP}_{1}\left(T_{1}, T\right)=\mathrm{NP}_{2}\left(T_{1}, T\right)=\mathrm{NP}_{3}\left(T_{1}, T\right)$.

Case 2. Setting the values of $M$ and $N$ to zero, we would have the traditional inventory system with backorder where the payments are settled without delay. In this case, $I_{c}$ refers to the opportunity cost the retailer incurs for keeping the inventory in his stock during the positive inventory time. So, the model for traditional inventory system with backorder is

$$
\begin{aligned}
& \mathrm{NP}_{1}\left(T_{1}, T\right) \\
& =\frac{1}{T}\left\{(s-c)\left[a T+\frac{b}{2} T^{2}\right]-A-\left(h+c I_{c}\right)\left(\frac{a}{2} T^{2}+\frac{b}{3} T^{3}\right)\right\} .
\end{aligned}
$$

\section{Solution Procedure}

Since analytical solving of the nonlinear formulated model in Section 3 is difficult, we have employed a metaheuristic algorithm to find the proper values for $T_{1}, T, Q_{1}$, and $Q$, while the net profit is maximized. Recently, genetic algorithm has attracted considerable attention and has been used successfully to the supply chain related problems (see $[30,31]$ ). So, we apply genetic algorithm here to determine the proper replenishment strategy.

GA starts with a population of a set of randomly produced representative solutions to the problem going to be solved.
Each individual is called a chromosome and consists of a string of symbols. These chromosomes evolve through succeeding iterations, known as generations, and their fitness is evaluated in every generation. Then, genetic operators including crossover, mutation, and selection are used to create offspring, population of the next generation. Crossover combines the information of the two candidate solutions of the parents by exchanging alternate pairs of their accidentally selected crossing sites to produce two offspring. In mutation, the values of a chromosome's genes would be changed randomly and selection reproduces the new population by the most highly ranked chromosomes of the existing generation. Using these evolutionary operators, GA is able to modify and pass on the best solutions to the next population. Hence, each generation yields improved offspring and generally the population moves to better solutions, ideally to the global optimum [32]. Pseudocode 1 illustrates the pseudocode of the proposed algorithm.

The parameters of the applied algorithm are set to the following values. Population size, probability of mutation, and probability of crossover are equal to 150,0.02, and 0.8, respectively. For assuring that $T_{1}$ is smaller than $T$, penalty method with the value $10^{15}$ is used. The algorithm continues till the termination criterion is met; it is met when the number of the iterations reaches 1000 . Moreover, for restricting the values of the variables $\left(T_{1}\right.$ and $\left.T\right)$ and getting better results, the maximum value is considered 0.2. Compared with the cases of higher limits, this value resulted in better net profit for the applied examples in Section 6.

\section{Numerical Examples}

Following the four examples provided in Teng et al. [29], we present some numerical examples in this section to show the results of the applied genetic algorithm, examine whether 
TABLE 7: Obtained replenishment policy for Example 4.

\begin{tabular}{|c|c|c|c|c|c|c|}
\hline & $c_{b}$ & 5 & 10 & 15 & 20 & 25 \\
\hline \multirow{5}{*}{$N=1 / 15$} & $T_{1}$ & 0.0795 & 0.0820 & 0.0841 & 0.0834 & 0.0837 \\
\hline & $T$ & 0.0941 & 0.0895 & 0.0892 & 0.0872 & 0.0867 \\
\hline & $Q_{1}$ & 289.9633 & 299.2573 & 306.8219 & 304.4183 & 305.3441 \\
\hline & $Q$ & 343.9493 & 327.0806 & 325.8445 & 318.5614 & 316.6962 \\
\hline & NP & $1591.4617^{*}$ & $1580.4222^{*}$ & 1576.4328 & 1574.4111 & 1573.1648 \\
\hline \multirow{5}{*}{$N=1 / 14$} & $T_{1}$ & 0.0796 & 0.0821 & 0.0829 & 0.0835 & 0.0838 \\
\hline & $T$ & 0.0942 & 0.0896 & 0.0880 & 0.0873 & 0.0868 \\
\hline & $Q_{1}$ & 290.4614 & 299.6770 & 302.5949 & 304.7477 & 305.7191 \\
\hline & $Q$ & 344.2597 & 327.3980 & 321.2614 & 318.8368 & 317.0280 \\
\hline & NP & $1591.0349^{*}$ & $1580.0848^{*}$ & $1576.1503^{*}$ & 1574.1244 & 1572.8887 \\
\hline \multirow{5}{*}{$N=1 / 13$} & $T_{1}$ & 0.0798 & 0.0820 & 0.0831 & 0.0836 & 0.0838 \\
\hline & $T$ & 0.0942 & 0.0894 & 0.0881 & 0.0873 & 0.0869 \\
\hline & $Q_{1}$ & 290.9395 & 299.0856 & 303.2486 & 305.0162 & 305.9744 \\
\hline & $Q$ & 344.5000 & 326.5366 & 321.8018 & 319.0373 & 317.2285 \\
\hline & NP & $1590.6303^{*}$ & $1579.7860^{*}$ & $1575.8928^{*}$ & 1573.8874 & 1572.6645 \\
\hline
\end{tabular}

${ }^{*} \mathrm{NP}=\mathrm{NP}_{2}$. For the rest, $\mathrm{NP}=\mathrm{NP}_{1}$.

TABLE 8: Obtained replenishment policy for the traditional case of Example 4.

\begin{tabular}{lccccc}
\hline$c_{b}$ & 5 & 10 & 15 & 20 & 25 \\
\hline$T_{1}$ & 0.0754 & 0.0780 & 0.0789 & 0.0794 & 0.0797 \\
$T$ & 0.0902 & 0.0856 & 0.0840 & 0.0833 & 0.0828 \\
$Q_{1}$ & 274.9067 & 284.2815 & 287.7354 & 289.5310 & 290.6344 \\
$Q$ & 329.5883 & 312.5334 & 306.7940 & 303.9124 & 302.1825 \\
$\mathrm{NP}$ & 1580.7096 & 1568.8370 & 1564.5468 & 1562.3322 & 1560.9801 \\
\hline
\end{tabular}

the proposed EOQ model under two-level trade credit with backorder is profitable to the retailer, test the sensitivity of the model to the changes of the input parameters, and compare the results with the model of Teng et al. [29] and the traditional EOQ inventory system with backorder.

Example 1. Suppose that $a=3600$ units, $b=2400, M=1 / 12$ year, $s=\$ 1$ per unit, $c=\$ 0.5$ per unit, $A=\$ 10$ per order, $h=$ $\$ 0.5$ per unit per year, $I_{c}=\$ 0.155$ per year, and $I_{e}=\$ 0.08$ per year. Applying genetic algorithm, the proper replenishment policy and net profit of the retailer for different values of $N$ and $c_{b}$ are calculated and shown in Table 1.

Special Cases. (i) Example 1 presented in Teng et al. [29] is a special case of this example in which $N=0, c_{b}=0$, and $T_{1}=$ $T$. The result of GA for this case is $T=0.1340, Q=503.7677$, and $\mathrm{NP}_{1}=1682.7105$ which was also obtained in Teng et al. [29].

(ii) Zero values for $M$ and $N$ leads this example to the conventional inventory system with shortage in which no delay in payment is assumed. The results of this special case are shown in Table 2.

Example 2. Considering the second example of Teng et al. [29], we have $D=3600+2400 t$ units, $M=1 / 12$ year, $s=\$ 1$ per unit, $c=\$ 0.5$ per unit, $A=\$ 10$ per order, $h=$ $\$ 1$ per unit per year, $I_{c}=\$ 0.13$ per year, and $I_{e}=\$ 0.08$ per year. Table 3 shows the solutions obtained for this example when backorder and customers' trade credit are assumed in the model.

Special Cases. (i) One of the special cases of this example when $N=0, c_{b}=0$, and $T_{1}=T$ reports the same results of the second example of Teng et al. [29] as $T=0.0823$, $\mathrm{Q}=304.2236$, and $\mathrm{NP}_{3}=1586.6884$.

(ii) The results of traditional inventory system with allowable shortages of Example 2 when $M=N=0$ are presented in Table 4.

Example 3. Suppose that $a=3600$ units, $b=2300, M=$ $1 / 7.5$ year, $s=\$ 1$ per unit, $c=\$ 0.5$ per unit, $A=\$ 10.2278$ per order, $h=\$ 0.5$ per unit per year, $I_{c}=\$ 0.17$ per year, and $I_{e}=$ $\$ 0.08$ per year. With different values assigned to $N$ and $c_{b}$, the solutions obtained for this example by GA are demonstrated in Table 5.

Special Cases. (i) Considering zero values for $N$ and $c_{b}$ and setting $T_{1}=T$, the optimal replenishment policy determined by $\mathrm{GA}$ is as $T=0.1333, \mathrm{Q}=500.4455$, and $\mathrm{NP}_{1}=\mathrm{NP}_{3}=$ 1692.8885 which is identical to the results of Teng et al. [29].

(ii) Table 6 presents the obtained ordering policy for the case that no delay in payment is assumed to show the conventional inventory system with backorder.

Example 4. Suppose the fourth example of Teng et al. [29] in which $a=3600$ units, $b=1200, M=1 / 12$ year, $s=\$ 1$ per unit, $c=\$ 0.5$ per unit, $A=\$ 10$ per order, $h=\$ 0.9$ per unit per year, $I_{c}=\$ 0.16$ per year, and $I_{e}=\$ 0.08$ per year. The solutions of this data set, when $N$ and $c_{b}$ are included in the model, are represented in Table 7. 
TABLE 9: Obtained replenishment policy for Example 5.

\begin{tabular}{|c|c|c|c|c|c|c|c|}
\hline$I_{c}$ & $h$ & $c_{b}$ & 5 & 10 & 15 & 20 & 25 \\
\hline \multirow{5}{*}{0.13} & \multirow{5}{*}{0.9} & $T_{1}$ & 0.0758 & 0.0784 & 0.0792 & 0.0801 & 0.0801 \\
\hline & & $T$ & 0.0907 & 0.0860 & 0.0844 & 0.0840 & 0.0832 \\
\hline & & $Q_{1}$ & 276.4047 & 285.7800 & 288.8577 & 292.1710 & 292.1543 \\
\hline & & $Q$ & 331.3114 & 314.1828 & 307.9850 & 306.7559 & 303.7719 \\
\hline & & $\mathrm{NP}$ & 1668.4121 & 1656.4728 & 1652.1599 & 1649.9317 & 1648.5752 \\
\hline \multirow{5}{*}{0.16} & \multirow{5}{*}{1} & $T_{1}$ & 0.0711 & 0.0737 & 0.0747 & 0.0751 & 0.0755 \\
\hline & & $T$ & 0.0864 & 0.0816 & 0.0800 & 0.0791 & 0.0787 \\
\hline & & $Q_{1}$ & 258.9127 & 268.4857 & 272.0984 & 273.6748 & 275.1391 \\
\hline & & $Q$ & 315.5950 & 297.8718 & 291.9541 & 288.5273 & 287.1792 \\
\hline & & NP & 1657.2806 & 1643.8682 & 1638.9849 & 1636.4554 & 1634.9095 \\
\hline
\end{tabular}

In the whole table $\mathrm{NP}=\mathrm{NP}_{3}$.

TABLE 10: Obtained replenishment policy for the traditional case of Example 5.

\begin{tabular}{|c|c|c|c|c|c|c|c|}
\hline$I_{c}$ & $h$ & $c_{b}$ & 5 & 10 & 15 & 20 & 25 \\
\hline \multirow{5}{*}{0.13} & \multirow{5}{*}{0.9} & $T_{1}$ & 0.0762 & 0.0787 & 0.0796 & 0.0801 & 0.0804 \\
\hline & & $T$ & 0.0909 & 0.0863 & 0.0848 & 0.0840 & 0.0835 \\
\hline & & $Q_{1}$ & 277.8044 & 287.1020 & 290.5287 & 292.3346 & 293.3977 \\
\hline & & $Q$ & 332.2228 & 315.2022 & 309.4800 & 306.6227 & 304.8784 \\
\hline & & NP & 1582.4520 & 1570.7982 & 1566.5921 & 1564.4219 & 1563.0974 \\
\hline \multirow{5}{*}{0.16} & \multirow{5}{*}{1} & $T_{1}$ & 0.0707 & 0.0733 & 0.0743 & 0.0748 & 0.0755 \\
\hline & & $T$ & 0.0859 & 0.0813 & 0.0797 & 0.0789 & 0.0788 \\
\hline & & $Q_{1}$ & 257.3913 & 267.2165 & 270.8610 & 272.7613 & 275.2462 \\
\hline & & $Q$ & 313.7748 & 296.4620 & 290.6188 & 287.6816 & 287.2915 \\
\hline & & NP & 1569.6400 & 1556.2955 & 1551.4351 & 1548.9178 & 1547.3752 \\
\hline
\end{tabular}

Special Cases. (i) When $N=c_{b}=0$ and $T_{1}=T$, the fourth example of Teng et al. [29] is a special case of this example and the equivalent solutions obtained here by GA are $T=0.0810$, $Q=295.5996$, and $\mathrm{NP}_{3}=1579.7113$.

(ii) The results of the traditional inventory system with backorder for Example 4 are shown in Table 8, when $M$ and $N$ are equal to zero.

Example 5. Suppose that $a=3600$ units, $b=1200, M=1 / 2$ year, $N=1 / 5$ year, $s=\$ 1$ per unit, $c=\$ 0.5$ per unit, $A=\$ 10$ per order, and $I_{e}=\$ 0.08$ per year. The replenishment policies for different values of $h, I_{c}$, and $c_{b}$ are shown in Table 9.

Special Cases. (i) When $N=c_{b}=0$ and $T_{1}=T$, Teng et al. [29] is a special case of this example and the solutions found are the following.

For $I_{c}=\$ 0.13$ and $h=0.9, T=0.0815, Q=297.5441$, and $\mathrm{NP}_{3}=1701.3369$.

For $I_{c}=\$ 0.16$ and $h=1, T=0.0770, Q=280.7654$, and $\mathrm{NP}_{3}=1686.8285$.

(ii) The results of the traditional inventory system for Example 5 are shown in Table 10, when $M$ and $N$ are equal to zero.

Comparing the results of the examples for the proposed inventory system with two-level trade credit and allowable shortages with the results obtained by Teng et al. [29] illustrates that, for some values of backorder cost, the proposed model in this paper is more profitable to the retailer. It is profitable to the point that the effects of not paying the inventory holding cost and the charged interest during the backorder period outweigh the cost of shortages. As it is expected, the examples show that the retailer's net profit decreases with the increase of the backorder cost.

Moreover, the net profit earned by the retailer in the twolevel trade credit is more than that earned by the same model without delay in payment which is because of the fact that the retailer does not tie up his capital in inventory and can earn interest when the payment is made with delay.

\section{Conclusion}

For matching the real world inventory systems, this paper extends the model proposed by Teng et al. [29] to the case of two-level trade credit with backorder. The formulated model is then solved by applying genetic algorithm and its validity is proved by solving the same examples reported in Teng et al. [29]. Comparing the results of this paper with that of Teng et al. [29] demonstrates that it can be more profitable when backorder cost is smaller than or equal to a specific value. Moreover, comparing with the traditional inventory system with backorder, the trade credit, both the model of Teng et al. 
[29] and the one proposed in this paper, would increase the profit of the retailer.

The presented inventory model of this paper can be extended in several ways. For example, deteriorating items can be considered. Moreover, the system may be generalized for partial backlogging shortages. In addition, developing a two-echelon supply chain inventory system consisting of a supplier and a retailer would be of great research interest.

\section{Conflict of Interests}

The authors declare that there is no conflict of interests regarding the publication of this paper.

\section{Acknowledgment}

This research is supported by the University Putra Malaysia.

\section{References}

[1] F. W. Harris, "How many parts to make at once," Factory, The Magazine of Management, vol. 10, no. 2, pp. 135-136, 1913.

[2] C. H. Glock, E. H. Grosse, and J. M. Ries, "The lot sizing problem: a tertiary study," International Journal of Production Economics, vol. 155, pp. 39-51, 2014.

[3] D. Piasecki, Consignment Inventory: What Is It and When Does It Make Sense to Use It? White Paper, Inventory Operations Consulting LLC, 2004.

[4] Z. Molamohamadi, M. Rezaeiahari, and N. Ismail, "Consignment inventory: review and critique of literature," Journal of Basic and Applied Scientific Research, vol. 3, no. 6, pp. 707-714, 2013.

[5] D. Seifert, R. W. Seifert, and M. Protopappa-Sieke, "A review of trade credit literature: opportunities for research in operations," European Journal of Operational Research, vol. 231, no. 2, pp. 245-256, 2013.

[6] Z. Molamohamadi, N. Ismail, Z. Leman, and N. Zulkifli, "Reviewing the literature of inventory models under trade credit contact," Discrete Dynamics in Nature and Society, vol. 2014, Article ID 975425, 19 pages, 2014.

[7] S. K. Goyal, "Economic order quantity under conditions of permissible delay in payments," Journal of the Operational Research Society, vol. 36, no. 4, pp. 335-338, 1985.

[8] S. P. Aggarwal and C. K. Jaggi, "Ordering policies of deteriorating items under permissible delay in payments," Journal of the Operational Research Society, vol. 46, no. 5, pp. 658-662, 1995.

[9] A. M. M. Jamal, B. R. Sarker, and S. Wang, "An ordering policy for deteriorating items with allowable shortage and permissible delay in payment," Journal of the Operational Research Society, vol. 48, no. 8, pp. 826-833, 1997.

[10] J.-T. Teng, "On the economic order quantity under conditions of permissible delay in payments," Journal of the Operational Research Society, vol. 53, no. 8, pp. 915-918, 2002.

[11] K.-J. Chung and Y.-F. Huang, "The optimal cycle time for EPQ inventory model under permissible delay in payments," International Journal of Production Economics, vol. 84, no. 3, pp. 307-318, 2003.

[12] Y.-F. Huang, "Optimal retailer's ordering policies in the EOQ model under trade credit financing," Journal of the Operational Research Society, vol. 54, no. 9, pp. 1011-1015, 2003.
[13] Y.-F. Huang, "An inventory model under two levels of trade credit and limited storage space derived without derivatives," Applied Mathematical Modelling, vol. 30, no. 5, pp. 418-436, 2006.

[14] J.-T. Teng and S. K. Goyal, "Optimal ordering policies for a retailer in a supply chain with up-stream and down-stream trade credits," Journal of the Operational Research Society, vol. 58, no. 9, pp. 1252-1255, 2007.

[15] Y.-F. Huang, "Economic order quantity under conditionally permissible delay in payments," European Journal of Operational Research, vol. 176, no. 2, pp. 911-924, 2007.

[16] Y.-F. Huang, "Optimal retailer's replenishment decisions in the EPQ model under two levels of trade credit policy," European Journal of Operational Research, vol. 176, no. 3, pp. 1577-1591, 2007.

[17] J.-T. Teng and C.-T. Chang, "Optimal manufacturer's replenishment policies in the EPQ model under two levels of trade credit policy," European Journal of Operational Research, vol. 195, no. 2, pp. 358-363, 2009.

[18] C.-H. Su, "An integrated supplier-buyer inventory model with conditionally free shipment under permissible delay in payments," Abstract and Applied Analysis, vol. 2010, Article ID 594246, 20 pages, 2010.

[19] C.-Y. Dye and L.-Y. Ouyang, "A particle swarm optimization for solving joint pricing and lot-sizing problem with fluctuating demand and trade credit financing," Computers \& Industrial Engineering, vol. 60, no. 1, pp. 127-137, 2011.

[20] C.-Y. Dye, "A finite horizon deteriorating inventory model with two-phase pricing and time-varying demand and cost under trade credit financing using particle swarm optimization," Swarm and Evolutionary Computation, vol. 5, pp. 37-53, 2012.

[21] G. C. Mahata, "An EPQ-based inventory model for exponentially deteriorating items under retailer partial trade credit policy in supply chain," Expert Systems with Applications, vol. 39, no. 3, pp. 3537-3550, 2012.

[22] K.-R. Lou and L. Wang, "Optimal lot-sizing policy for a manufacturer with defective items in a supply chain with upstream and down-stream trade credits," Computers \& Industrial Engineering, vol. 66, no. 4, pp. 1125-1130, 2013.

[23] Z. Molamohamadi, R. Arshizadeh, and N. Ismail, "An EPQ inventory model with allowable shortages for deteriorating items under trade credit policy," Discrete Dynamics in Nature and Society, vol. 2014, Article ID 476085, 10 pages, 2014.

[24] M.-S. Chern, Y.-L. Chan, J.-T. Teng, and S. K. Goyal, "Nash equilibrium solution in a vendor-buyer supply chain model with permissible delay in payments," Computers \& Industrial Engineering, vol. 70, no. 1, pp. 116-123, 2014.

[25] M.-S. Chern, Q. Pan, J.-T. Teng, Y.-L. Chan, and S.-C. Chen, "Stackelberg solution in a vendor-buyer supply chain model with permissible delay in payments," International Journal of Production Economics, vol. 144, no. 1, pp. 397-404, 2013.

[26] S.-C. Chen and J.-T. Teng, "Retailer's optimal ordering policy for deteriorating items with maximum lifetime under supplier's trade credit financing," Applied Mathematical Modelling, vol. 38, no. 15-16, pp. 4049-4061, 2014.

[27] S.-C. Chen, J.-T. Teng, and K. Skouri, "Economic production quantity models for deteriorating items with up-stream full trade credit and down-stream partial trade credit," International Journal of Production Economics, vol. 155, pp. 302-309, 2014.

[28] S.-C. Chen, L. E. Cárdenas-Barrón, and J.-T. Teng, "Retailer's economic order quantity when the supplier offers conditionally 
permissible delay in payments link to order quantity," International Journal of Production Economics, vol. 155, pp. 284-291, 2014.

[29] J.-T. Teng, J. Min, and Q. Pan, "Economic order quantity model with trade credit financing for non-decreasing demand," Omega, vol. 40, no. 3, pp. 328-335, 2012.

[30] X. Chen, W. Wan, and X. Xu, "Modeling rolling batch planning as vehicle routing problem with time windows," Computers \& Operations Research, vol. 25, no. 12, pp. 1127-1136, 1998.

[31] Y.-B. Park, "A hybrid genetic algorithm for the vehicle scheduling problem with due times and time deadlines," International Journal of Production Economics, vol. 73, no. 2, pp. 175-188, 2001.

[32] M. Gen and R. Cheng, Genetic Algorithms and Engineering Design, John Wiley \& Sons, New York, NY, USA, 1997. 


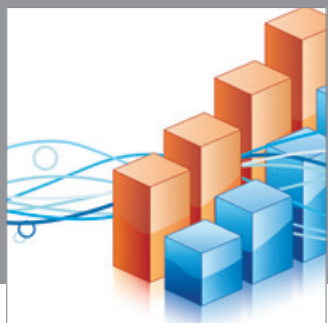

Advances in

Operations Research

mansans

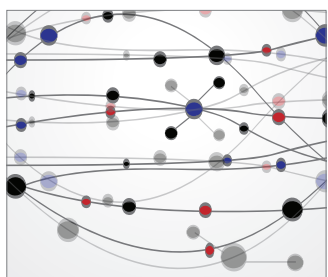

The Scientific World Journal
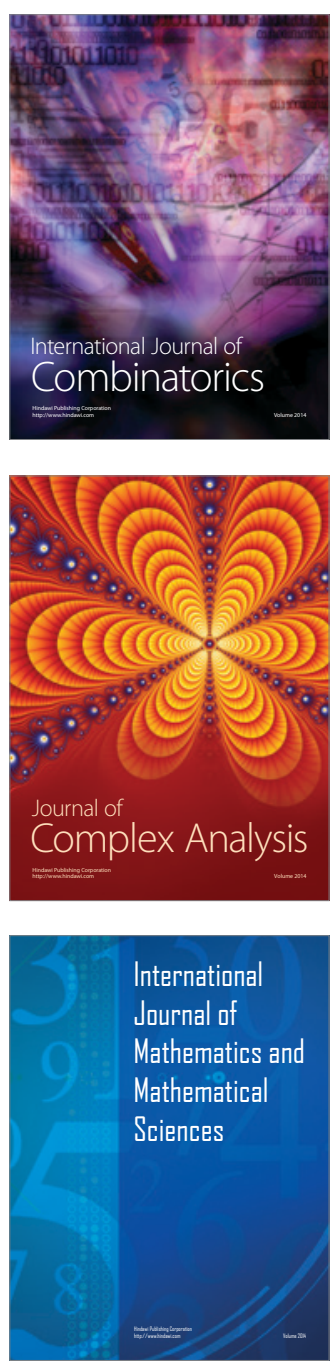
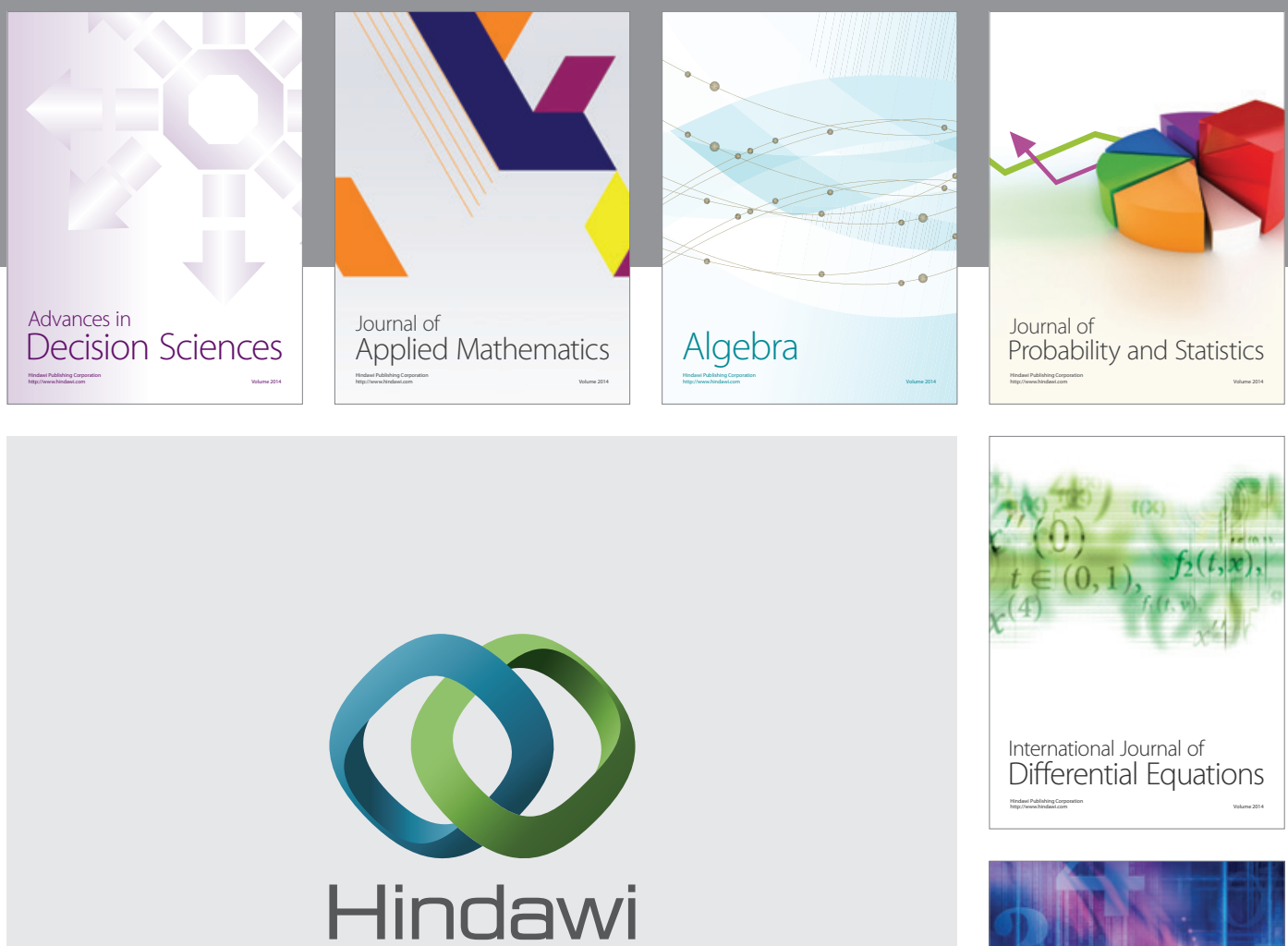

Submit your manuscripts at http://www.hindawi.com
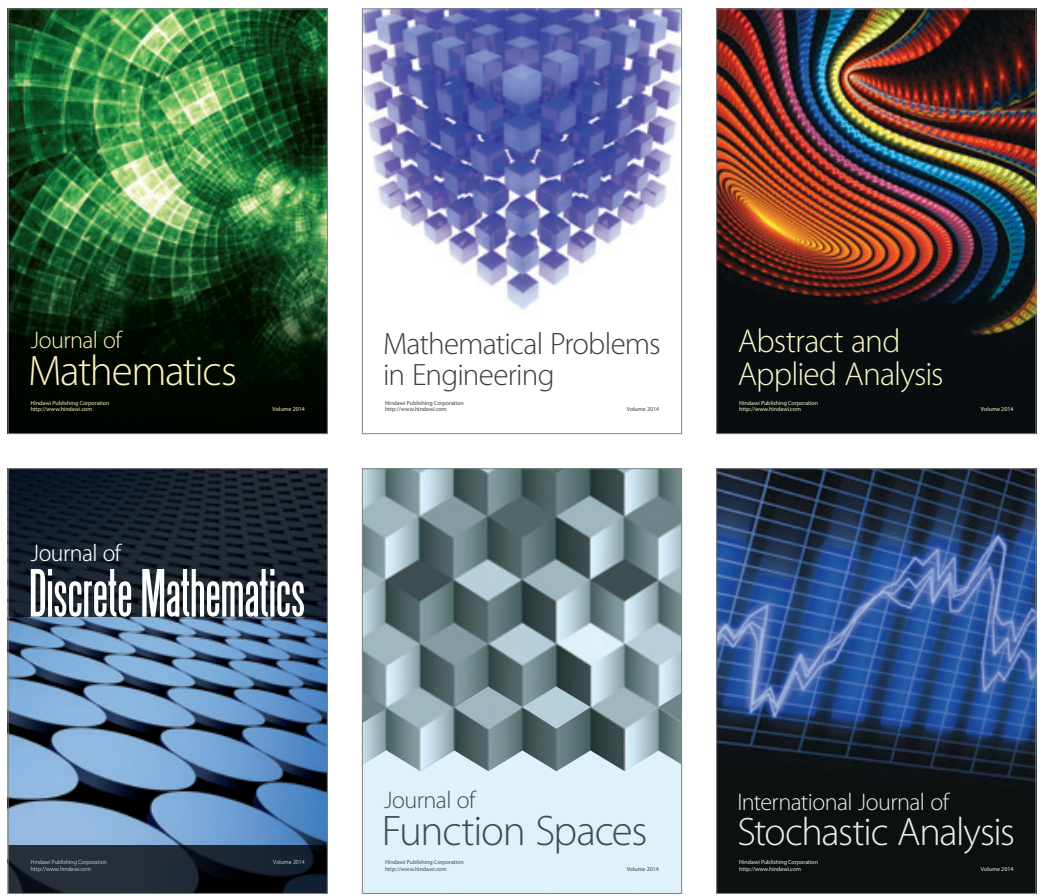

Journal of

Function Spaces

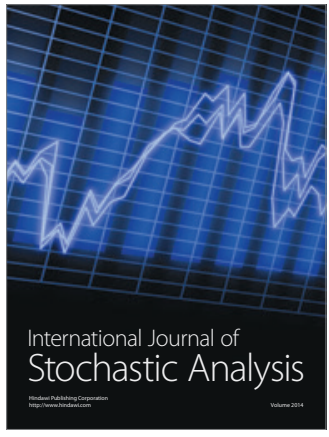

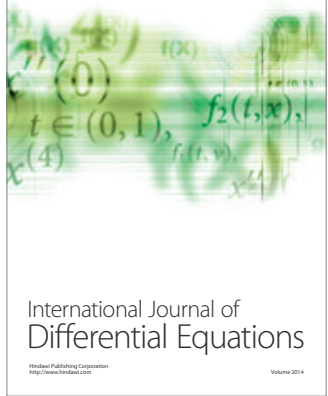
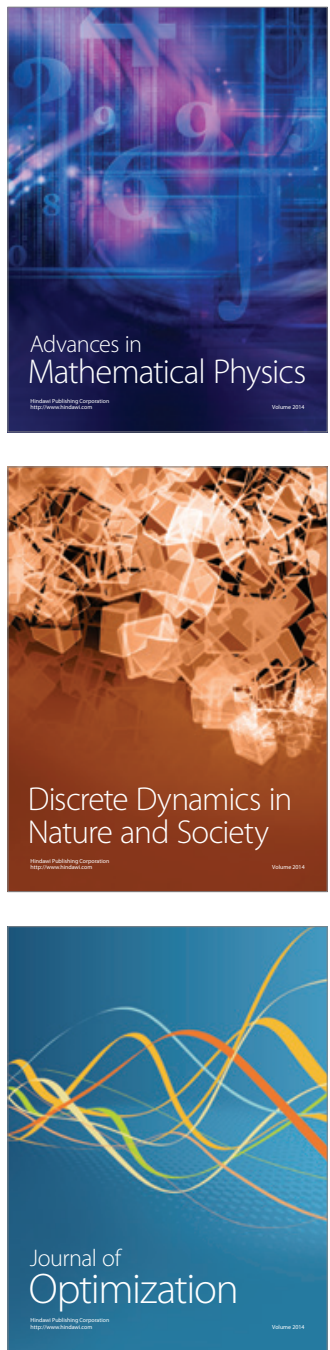